\title{
Exercise Training, Lymphocyte Subsets and Their Cytokines Production: Experience of an Italian Professional Football Team and Their Impact on Allergy
}

\author{
Stefano R. Del Giacco, ${ }^{1}$ Marco Scorcu, ${ }^{2,3}$ Federico Argiolas, ${ }^{4}$ \\ Davide Firinu, ${ }^{1}$ and G. Sergio Del Giacco ${ }^{1}$ \\ ${ }^{1}$ Department of Medical Sciences "M. Aresu”, University of Cagliari, Asse Didattico "E1", Cittadella Universitaria, \\ Monserrato, 09042 Cagliari, Italy \\ ${ }^{2}$ National Health Service, ASL 6, 09025 Sanluri, Italy \\ ${ }^{3}$ Cagliari Calcio Football Club, 09123 Cagliari, Italy \\ ${ }^{4}$ National Health Service, ASL 8 Public Health Services, "Businco” Hospital, 09121 Cagliari, Italy \\ Correspondence should be addressed to Stefano R. Del Giacco; stedg@medicina.unica.it
}

Received 28 February 2014; Revised 26 May 2014; Accepted 28 May 2014; Published 23 June 2014

Academic Editor: Fulvio Braido

Copyright (C) 2014 Stefano R. Del Giacco et al. This is an open access article distributed under the Creative Commons Attribution License, which permits unrestricted use, distribution, and reproduction in any medium, provided the original work is properly cited.

\begin{abstract}
Background. In recent years, numerous articles have attempted to shed light on our understanding of the pathophysiological mechanisms of exercise-induced immunologic changes and their impact on allergy and asthma. It is known that lymphocyte subclasses, cytokines, and chemokines show modifications after exercise, but outcomes can be affected by the type of exercise as well as by its intensity and duration. Interesting data have been presented in many recent studies on mouse models, but few studies on humans have been performed to check the long-term effects of exercise over a whole championship season. Methods. This study evaluated lymphocyte subsets and their intracellular IL-2, IL- 4 , TNF- $\alpha$, and IFN- $\gamma$ production in professional football (soccer) players, at three stages of the season, to evaluate if alterations occur, particularly in relation to their allergic status. Results and Conclusion. Despite significant mid-season alterations, no significant lymphocyte subclasses count modifications, except for NKs that were significantly higher, were observed at the end. IL-2 and IL- 4 producing cells showed a significant decrease $(P=0.018$ and $P=0.001$, but in a steady fashion for IL-4), confirming the murine data about the potential beneficial effects of aerobic exercise for allergic asthma.
\end{abstract}

\section{Introduction}

In recent years, the search for new training methods to obtain maximum performance in sports has become of fundamental interest to trainers and athletes, and the study of exercise immunology has become part of this strategy. In fact, exercise-induced immune modifications may show a wide range of changes $[1,2]$, influencing positively or negatively an athlete's health. On the one hand, they may lead to an increased risk of infections (the "open window" theory) [3]; on the other hand, the positive effect of regular exercise on immune changes has been recently demonstrated in findings on experimental mouse models [4]. Both innate and acquired immunity are influenced by exercise. Studies performed to date in the field of "exercise immunology" explored many variables such as "acute" versus "prolonged" exercise, different sports, age, and recreational versus professional athletes. The effect of chronic exercise has been studied longitudinally after at most few months of training and often in subjects previously untrained or affected by chronic diseases $[5,6]$.

During acute exercise, modifications in mononucleated blood cells occur [7]. Increased levels of all the lymphocyte subsets have been found and some authors have reported a fall in the CD4/CD8 ratio [6]. At the end of the exercise, values fall to below-normal levels; according to a number of authors both the duration and the reduction depend on 
the intensity and duration of the exercise itself [1]. Natural Killer (NK) cells, the most responsive immune cells to acute exercise, show a striking exercise-induced increase, whereas their cell count drops to below half the normal level after exercise $[8,9]$. Their cytotoxicity increases during exercise, but it is depressed after exercise, probably augmenting the susceptibility to infections [10-12].

The production of cytokines increases in response to acute exercise. Proinflammatory cytokines (IL-1, IL-6 and TNF- $\alpha$ ) concentrations rise after prolonged exercise (a $20 \mathrm{Km}$ run, for instance); increased IL- $1 \beta$ is found in the muscular tissue; and increased IL-1 activity can be noted (muscular proteolysis?), even if a suppression of their production one hour after exercise has been reported by other authors $[6,13]$. Recent cross-sectional data described increased NGF serum levels in top athletes [14]. Additionally, recent findings are leading to interesting new theories on the anti-inflammatory effect of regular, moderate exercise. Lower levels of Th2 cytokines and enhanced Th-1 and T-reg responses in murine models of asthma performing aerobic exercise versus sedentary mice have been reported in recent studies $[4,15,16]$.

Limited data have been published on the immunological effects of regular exercise ex vivo in top athletes and in amateurs during a longer time span, such as an entire training season, avoiding overtrained subjects $[17,18]$. Therefore, the aim of this study was to evaluate lymphocyte subsets and their intracellular IL-2, IL-4, TNF- $\alpha$, and IFN- $\gamma$ production in professional soccer players during an entire league championship. We obtained blood samples at three stages of the championship season, to verify whether alterations occur, and what the clinical relevance of these modifications could be, in particular in relation to their allergic status.

\section{Materials and Methods}

All players (29 athletes) of an Italian "Serie A" (Premier League) football (soccer) team underwent blood sampling (at rest, before training, and 72 hours after a match) before the start of season (June), halfway through the season (January) and at the end of season (May), respectively. All the subjects were checked through the $A Q U A^{\odot}$ validated allergy questionnaire for athletes [19]. Informed consent was obtained from all participants and the study protocol was approved by the Ethics Committee of the University Hospital. Analysis of the collected samples was performed using a Becton Dickinson FACSCalibur Immunocytometry System (Franklin Lakes, USA). For lymphocyte subsets, a Multi-Test IMK Kit (Becton Dickinson), that is a fourcolour direct immunofluorescence reagent kit for identifying and determining the percentages and absolute counts of mature human lymphocyte subsets, was used. Fluorochromelabelled antibodies (CD45RA-FITC, CD45R0-FITC, CD62L$\mathrm{PE}, \mathrm{CD} 3$ PerCP, CD4-APC, and CD8-APC) that bind specifically to the leukocyte surface antigens were employed: T Lymphocytes (CD3+), B lymphocytes (CD19+), helper/inducer T lymphocytes (CD3+, CD4+), suppressor/cytotoxic T lymphocytes (CD3+, CD8+), and Natural Killer lymphocytes (CD3- CD16+ and $\mathrm{NK}$ or CD56+). CD4+ T-cells were studied for intracellular cytokines production allowing us to distinguish the functionally polarized cells through their cytokine secretion pattern.

For each of the athletes, data regarding the proportion of cytokines producing lymphocytes (IL-2, IFN- $\gamma$, TNF$\alpha$, and IL-4) and the lymphocyte subpopulations (absolute count and proportion of NK, CD3, CD4, CD8, and CD19) were compared by analysing their variation in the three consecutive blood samples.

\section{Statistical Analysis}

Considering the number of cases $(<30)$, in order to test the significance of the differences, the Wilcoxon Signed Ranks Test was used. Values of two consecutive samples were compared (1st sample versus 2nd sample, and 2nd sample versus 3rd sample); furthermore, values obtained at the beginning of the season were compared with values obtained at the end (1st sample versus 3rd sample). $P<0.05$ was considered as significant. Percentages, medians, interquartile ranges, and " $P$ values" are shown in the results tables. Data were processed through SPSS (Release 20.0, Copyright (CSPSS Inc., Chicago, IL, USA) for Windows.

\section{Results}

All the subjects were males, aged 17-30 years (mean age; 24.3 yrs). Of the 29 athletes that at any moment could have been part of the team, 16 underwent 3 blood samplings, 7 were present at least 2 consecutive samplings, 2 performed two nonconsecutive samplings (the first and the last), and 4 underwent only one blood sampling. Data of the subjects from the 3 first groups (25 athletes, $86 \%$ of the whole population studied) were taken into consideration to perform the statistical analysis. The last group (4 athletes, 14\%) was not considered for statistical purposes. Out of the whole group, 8 (28\%) had respiratory allergies (AQUA questionnaire, further confirmed by history, symptoms, and skin prick tests) and were undergoing treatment with inhaled corticosteroids and Beta-2 agonists. Seven out of the eight allergic athletes were included in the 25 subjects providing samples for the final analysis (Table 1).

The proportion of IL-2 and IL-4 producing lymphocytes showed statistically significant changes in each comparison between the three different moments of the championship (see Table 2). A significant decrease in IL-2 producing cells was seen at the middle of the championship. At the end of the observation period, cell percentage was still statistically significantly lower despite a slight increase (Table 2). A different pattern was observed with the IL-4 producing cells: a continuous and significant decrease from the beginning of the study to the end of the championship was witnessed (Table 2). The allergic athletes were the most involved in the IL-4 producing cell decrease (Figure 1). A comparison between allergic and nonallergic subjects is reported in Table 3. The only significance obtained for TNF- $\alpha$ and IFN- $\gamma$ producing cells is related to their increase between the middle of the championship and the last determination (Table 2). 
TABLE 1: Sensitizations in the allergic athletes selected (skin prick test).

\begin{tabular}{|c|c|c|}
\hline Sample numberAge & Sensitization(s) & Symptoms \\
\hline 25 & $\begin{array}{l}\text { Pellitory, Ragweed, } \\
\text { Cladosporium, Ash } \\
\text { tree }\end{array}$ & Rhinoconjunctivitis \\
\hline 26 & $\begin{array}{l}\text { House dust mites, } \\
\text { Dog }\end{array}$ & Rhinitis \\
\hline 20 & Grass, Pellitory, Cat & Asthma + Rhinitis \\
\hline 24 & $\begin{array}{l}\text { Grass, Olive, } \\
\text { Chenopodium }\end{array}$ & Asthma + Rhinitis \\
\hline 26 & $\begin{array}{l}\text { House dust mites, } \\
\text { Mugwort, Alternaria }\end{array}$ & $\begin{array}{l}\text { Asthma }+ \\
\text { Rhino-conjunctivitis }\end{array}$ \\
\hline 27 & Grass, Olive & Rhinoconjunctivitis \\
\hline 29 & $\begin{array}{l}\text { House dust mites, } \\
\text { Grass, Cypress }\end{array}$ & $\begin{array}{l}\text { Asthma }+ \\
\text { Rhinoconjunctivitis }\end{array}$ \\
\hline
\end{tabular}

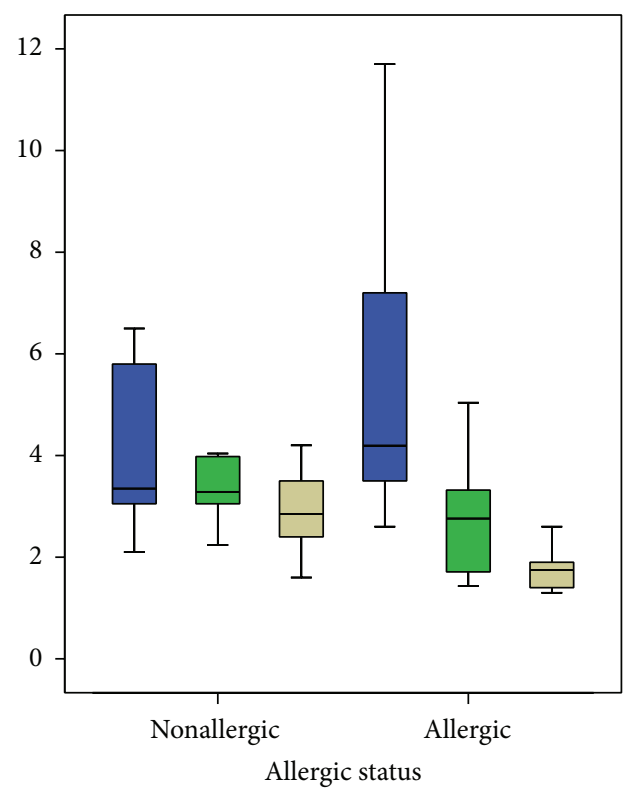

FIGURE 1: IL-4 producing lymphocytes \% (nonallergic versus allergic athletes) during the three timepoints of the season. The boxplots highlight a constant decrease of IL-4 producing lymphocytes from the beginning till the end of the championship. In the allergic group the final IL-4 producing cells proportion is lower even with higher basal values. Exact values can be checked in Table 3.

Comparisons between the cells absolute counts (Table 4) showed a similar pattern. All the lymphocyte subclasses counts at the middle of the championship were much higher than at the beginning ( $P$ always $<0.005)$. At the end of season, all the absolute counts showed a significant drop in comparison to the middle of the season ( $P$ always < 0.05 ), being much similar to those noticed at the beginning of the championship. CD3, CD4, and CD8 absolute counts did not show significant changes comparing the 1st to the 3rd samples $(P>0.05)$. NK cells absolute count remained significantly higher at the end of the championship $(P=$ 0.002). Regarding the differences between the percentages of lymphocytes subclasses, a statistically significant increase in the NK\% between the beginning and the middle of the championship is noticeable $(P<0.001)$; this increase remains significant at the end of the championship $(P=0.030)$. Contrarily, a significant decrease in the CD3\% $(P=0.001)$ and a slight, but significant, decrease in the CD4\% $(P=$ 0.024 ) is recorded (1st versus 2 nd sample); this decrease remains significant at the end of the championship (1st versus 3rd sample, CD3\% $P=0.033$ and $\mathrm{CD} 4 \% P=0.049)$. No significant changes were recorded for $\mathrm{CD} 8 \%$.

\section{Discussion}

The modifications highlighted in this study suggest that athletes performing a regular training program during the entire season, such as that performed by professional athletes, do not have a reduction of cell absolute counts. NK absolute count and percentage increase significantly. To our knowledge, data obtained in such a long timescale (one year) are scarce; the results reported in the present study may challenge, at least in part, the concept that the NK decrease in the recovery phase (a few hours after competitions) may be linked to an increased susceptibility to viral infections [20]. In particular, the reported NK reduction is clearly a transient phenomenon as it does not persist at a larger scale of observation such as the one presented in our data at six months and one year (Table 4). This finding could be in agreement with data reported in the literature showing an increased NK cell activity and no changes in upper respiratory infections incidence in professional athletes versus nonathletic controls $[18,21]$.

A reduced production of IL-2 in these athletes was observed: it could be speculated that the cells might become less reactive to antigenic stimuli [22] with a relative decreased immune reactivity. IL-2 is essential for extrathymic homeostasis of Treg Lymphocytes, which are central regulators also of allergic inflammation. However, a treatment of allergen-sensitized mice with recombinant IL-2 paradoxically increased airway eosinophilia and tissue inflammation in one study [23]. Therefore, our finding of reduced IL-2 production should be further investigated also for its effects on the Treg lymphocytes compartment.

Furthermore, in our study IL-4 producing cells are significantly reduced at the end of the season, in particular as regards the allergic athletes (Figure 1 and Table 3).

It is known that, among the several cytokines involved in the allergic asthma pathogenesis, IL- 4 plays a fundamental role $[24,25]$. Allergic individuals show a "TH2 family" cytokine pattern. The elaboration of TH-2 effector cytokines is dependent on IL-4 and IL-25 and their respective transcription factors GATA-3 [26], STAT-6 [27], and c-maf [28], whereas negative transcription occurs through cytokines that favour TH-1, such as IL-18 [29].

The growing number of studies on the murine model of allergic asthma shows that low to moderate intensity aerobic exercise decreases eosinophilic and lymphocytic inflammation in mice exercising for 4 weeks, 5 days a week, at $50 \%$ exercise capacity [4]. Aerobic exercise also seems 
TABLE 2: Cytokines producing lymphocytes (percentage)*

\begin{tabular}{lcccccc}
\hline & 1st sample & $P^{\S}($ 1st-2nd $)$ & 2nd sample & $P^{\S}$ (2nd-3rd) & 3rd sample & $P^{\S}(1 \mathrm{st}-3 \mathrm{rd})$ \\
\hline IL-2 & $22.80(14.80-26.65)$ & $\mathbf{0 . 0 0 1}$ & $11.63(9.57-15.39)$ & $\mathbf{0 . 0 0 1}$ & $16.20(12.20-20.25)$ \\
TNF- $\alpha$ & $31.00(24.05-39.05)$ & 0.107 & $25.88(20.01-31.08)$ & $\mathbf{0 . 0 1 5}$ & $29.75(22.65-33.75)$ \\
IFN- $\gamma$ & $12.30(10.10-15.70)$ & 0.445 & $12.30(9.33-15.23)$ & $\mathbf{0 . 0 0 8}$ & $14.70(10.90-18.35)$ & 0.184 \\
IL-4 & $4.19(3.03-5.70)$ & $\mathbf{0 . 0 1 4}$ & $3.23(2.21-3.51)$ & $\mathbf{0 . 0 0 1}$ & $2.45(1.68-2.98)$ & 0.569 \\
\hline
\end{tabular}

* Data are expressed in medians (interquartile range).

${ }^{\S}$ Wilcoxon Signed Ranks Test.

TABLE 3: Cytokines producing lymphocytes, allergic and nonallergic subjects (percentage)*

\begin{tabular}{|c|c|c|c|c|c|c|}
\hline & 1st sample & $P^{\S}(1 \mathrm{st}-2 \mathrm{nd})$ & 2nd sample & $P^{\S}(2 \mathrm{nd}-3 \mathrm{rd})$ & 3rd sample & $P^{\S}$ (1st-3rd) \\
\hline \multicolumn{7}{|c|}{ Allergic (7 subjects) } \\
\hline IL-2 & $20.80(10.80-26.20)$ & 0.063 & $12.16(9.87-16.06)$ & 0.028 & $17.25(13.50-24.95)$ & 0.463 \\
\hline TNF- $\alpha$ & $28.90(16.50-36.60)$ & 0.612 & $25.88(20.01-33.11)$ & 0.345 & $31.90(24.38-35.10)$ & 0.753 \\
\hline IFN- $\gamma$ & $14.40(12.30-15.40)$ & 0.091 & $12(9.33-14.68)$ & 0.028 & $15.30(11.18-19.98)$ & 0.500 \\
\hline $\mathrm{IL}-4$ & $4.19(2.60-7.20)$ & 0.042 & $2.21(1.58-3.32)$ & 0.028 & $1.75(1.38-2.08)$ & 0.028 \\
\hline \multicolumn{7}{|c|}{ Nonallergic (18 subjects) } \\
\hline IL-2 & $22.95(15.30-27.75)$ & 0.003 & $10.98(9.35-15.06)$ & 0.006 & $16.20(12.20-20.00)$ & 0.019 \\
\hline TNF- $\alpha$ & $31.55(26.98-41.38)$ & 0.008 & $26.36(18.55-31.06)$ & 0.022 & $28.45(22.55-32.18)$ & 0.041 \\
\hline IFN- $\gamma$ & $11.55(9.60-16.83)$ & 0.754 & $13.06(9.34-15.73)$ & 0.109 & $13.70(10.30-16.90)$ & 0.423 \\
\hline IL-4 & $3.85(3.04-5.65)$ & 0.091 & $3.29(2.82-3.82)$ & 0.009 & $2.70(2.03-3.43)$ & 0.021 \\
\hline
\end{tabular}

${ }^{*}$ Data are expressed in medians (interquartile range).

${ }^{\mathfrak{s}}$ Wilcoxon Signed Ranks Test.

TABLE 4: Peripheral lymphocyte subclasses (percentage and absolute count) ${ }^{*}$.

\begin{tabular}{|c|c|c|c|c|c|c|}
\hline & 1st sample & $P^{\S}(1 \mathrm{st}-2 \mathrm{nd})$ & 2nd sample & $P^{\S}(2 \mathrm{nd}-3 \mathrm{rd})$ & 3rd sample & $P^{\S}(1 \mathrm{st}-3 \mathrm{rd})$ \\
\hline \multicolumn{7}{|c|}{ Percentage } \\
\hline NK & $13(8-16)$ & $<0.001$ & $19(14-22)$ & 0.176 & $18(12-24)$ & 0.030 \\
\hline CD3 & $72(67-78)$ & 0.001 & $67(64-72)$ & 0.058 & $67(62-72)$ & 0.033 \\
\hline $\mathrm{CD} 4$ & $42(37-49)$ & 0.024 & $41(37-44)$ & 0.639 & $40(38-44)$ & 0.049 \\
\hline $\mathrm{CD} 8$ & $26(21-30)$ & 0.916 & $24(20-26)$ & 0.849 & $24(20-26)$ & 0.223 \\
\hline \multicolumn{7}{|c|}{ Absolute count } \\
\hline NK & $232(196-288)$ & $<0.001$ & $519(423-662)$ & $<0.001$ & $375(247-510)$ & 0.002 \\
\hline $\mathrm{CD} 3$ & $1416(1267-1678)$ & 0.001 & $1862(1682-2369)$ & 0.002 & $1442(1294-1707)$ & 0.679 \\
\hline $\mathrm{CD} 4$ & 876 (717-990) & 0.002 & 1135 (916-1245) & 0.010 & $868(749-1060)$ & 0.943 \\
\hline CD8 & $497(419-571)$ & $<0.001$ & $703(518-865)$ & 0.004 & $521(468-568)$ & 0.071 \\
\hline
\end{tabular}

* Data are expressed in medians (interquartile range).

${ }^{\S}$ Wilcoxon Signed Ranks Test.

to reduce airway remodeling, with reduced airway smooth muscle hypertrophy and hyperplasia $[4,30]$ (even if effects on remodeling were a matter of debate in another animal study [31]), a reduction in leukocyte infiltration, proinflammatory cytokine production, adhesion molecules expression [32], and enhanced regulatory T-cell (Treg) responses [16]. Aerobic exercise also shows an anti-inflammatory effect in mice exposed to air pollution [33]. A single session of moderate aerobic exercise can decrease airway inflammation (but not responsiveness) in mice, with a downregulation of inflammatory mediators' genes expression and Th-2 derived cytokines production [15]. Similar findings have also been demonstrated in one study on humans, where a reduction in neutrophils count in patients with chronic inflammatory conditions was observed [34]. Furthermore, a recent systematic review concludes that physical training improves airway inflammation in animal asthma models [35] and another study shows that it does not increase airway inflammation in children [36].

Our data, demonstrating for the first time a reduction of the IL-4 producing cells in professional athletes over a long time span of observation, could be in agreement with the data coming from the murine studies previously cited.

\section{Conclusion}

This is probably the first study to demonstrate the immunological modifications that occur in a long-term, real-life 
setting in professional athletes, and this undoubtedly represents one of its strengths. However, there are some limitations in this study, linked to the peculiar characteristics of professional athletes. The narrow age range and the maleonly population can reduce the interpersonal variability. Furthermore, the lack of a sedentary control population may also reduce the general value of these results, even if, to our knowledge, no significant physiologic seasonal changes in the parameters studied have been described in the general population [37-39].

In summary, the findings in this study suggest that normal lymphocyte percentages and counts are not impaired by a regular training program, such as that performed by professional trained athletes. The decrease of IL- 4 producing cells can be considered interesting as one of the factors for the improvement of symptoms in allergic and asthmatic people performing a regular training program [40]. Aerobic exercise training seems to be beneficial for allergic inflammation, and it may be suggested as a comprehensive part of the prevention and therapy strategies for asthmatics.

\section{Conflict of Interests}

The authors declare that there is no conflict of interests regarding the publication of this paper.

\section{Acknowledgment}

The authors wish to thank Mr. Barry Mark Wheaton for his invaluable linguistic assistance and Dr. Luisa Di Martino, Dr. Elisabetta Manca and Dr. Emma Muggianu for their technical support.

\section{References}

[1] N. P. Walsh, M. Gleeson, R. J. Shephard et al., "Position statement part one: immune function and exercise," Exercise Immunology Review, vol. 17, pp. 6-63, 2011.

[2] S. R. Del Giacco, K.-H. Carlsen, and G. Du Toit, "Allergy and sports in children," Pediatric Allergy and Immunology, vol. 23, no. 1, pp. 11-20, 2012.

[3] L. Hoffman-Goetz and B. K. Pedersen, "Exercise and the immune system: a model of the stress response?" Immunology Today, vol. 15, no. 8, pp. 382-387, 1994.

[4] R. P. Vieira, A. C. D. Toledo, S. C. Ferreira et al., "Airway epithelium mediates the anti-inflammatory effects of exercise on asthma," Respiratory Physiology and Neurobiology, vol. 175, no. 3, pp. 383-389, 2011.

[5] M. Kruijsen-Jaarsma, D. Révész, M. B. Bierings, L. M. Buffart, and T. Takken, "Effects of exercise on immune function in patients with cancer: a systematic review," Exercise Immunology Review, vol. 19, pp. 120-143, 2013.

[6] B. K. Pedersen and L. Hoffman-Goetz, "Exercise and the immune system: regulation, integration, and adaptation," Physiological Reviews, vol. 80, no. 3, pp. 1055-1081, 2000.

[7] M. Gleeson, "Immune function in sport and exercise," Journal of Applied Physiology, vol. 103, no. 2, pp. 693-699, 2007.

[8] Y. W. Lee, K. W. Shin, I.-Y. Paik et al., "Immunological impact of taekwondo competitions," International Journal of Sports Medicine, vol. 33, no. 1, pp. 58-66, 2012.
[9] S. R. Del Giacco, F. Tocco, F. Melis et al., "Responsiveness of human natural killer cells during acute, incremental exercise up to exhaustion," Sport Sciences for Health, vol. 1, pp. 36-40, 2004.

[10] S. R. Del Giacco, P. E. Manconi, and G. S. Del Giacco, "Allergy and sports," Allergy, vol. 56, no. 3, pp. 215-223, 2001.

[11] B. W. Timmons and T. Cieslak, "Human natural killer cell subsets and acute exercise: a brief review," Exercise Immunology Review, vol. 14, pp. 8-23, 2008.

[12] M. Gleeson and N. C. Bishop, "The T cell and NK cell immune response to exercise," Annals of Transplantation, vol. 10, no. 4, pp. 43-48, 2005.

[13] C. Weinstock, D. König, R. Harnischmacher, J. Keul, A. Berg, and H. Northoff, "Effect of exhaustive exercise stress on the cytokine response," Medicine and Science in Sports and Exercise, vol. 29, no. 3, pp. 345-354, 1997.

[14] M. Bonini, D. Fioretti, V. Sargentini et al., "Increased nerve growth factor serum levels in top athletes," Clinical Journal of Sport Medicine, vol. 23, no. 3, pp. 228-231, 2013.

[15] M. Hewitt, A. Creel, K. Estell, I. C. Davis, and L. M. Schwiebert, "Acute exercise decreases airway inflammation, but not responsiveness, in an allergic asthma model," American Journal of Respiratory Cell and Molecular Biology, vol. 40, no. 1, pp. 83-89, 2009.

[16] T. Lowder, K. Dugger, J. Deshane, K. Estell, and L. M. Schwiebert, "Repeated bouts of aerobic exercise enhance regulatory $\mathrm{T}$ cell responses in a murine asthma model," Brain, Behavior, and Immunity, vol. 24, no. 1, pp. 153-159, 2010.

[17] Z. Baj, J. Kantorski, E. Majewska et al., "Immunological status of competitive cyclists before and after the training season," International Journal of Sports Medicine, vol. 15, no. 6, pp. 319324, 1994.

[18] D. C. Nieman, S. L. Nehlsen-Cannarella, O. R. Fagoaga et al., "Immune functiom in female elite rowers and non-athletes," British Journal of Sports Medicine, vol. 34, no. 3, pp. 181-187, 2000.

[19] M. Bonini, F. Braido, I. Baiardini et al., "Aqua: allergy questionnaire for athletes. Development and validation," Medicine and Science in Sports and Exercise, vol. 41, no. 5, pp. 1034-1041, 2009.

[20] R. J. Shephard and P. N. Shek, "Effects of exercise and training on natural killer cell counts and cytolytic activity: a meta-analysis," Sports Medicine, vol. 28, no. 3, pp. 177-195, 1999.

[21] D. C. Nieman, "Is infection risk linked to exercise workload?" Medicine and Science in Sports and Exercise, vol. 32, no. 7, pp. S406-S411, 2000.

[22] S. L. Gaffen and K. D. Liu, "Overview of interleukin-2 function, production and clinical applications," Cytokine, vol. 28, no. 3, pp. 109-123, 2004.

[23] M. S. Wilson, J. T. Pesce, T. R. Ramalingam, R. W. Thompson, A. Cheever, and T. A. Wynn, "Suppression of murine allergic airway disease by IL-2: anti-IL-2 monoclonal antibody-induced regulatory T cells," Journal of Immunology, vol. 181, no. 10, pp. 6942-6954, 2008.

[24] L. P. Ngoc, D. R. Gold, A. O. Tzianabos, S. T. Weiss, and J. C. Celedón, "Cytokines, allergy, and asthma," Current Opinion in Allergy and Clinical Immunology, vol. 5, no. 2, pp. 161-166, 2005.

[25] N. Zimmermann, G. K. Hershey, P. S. Foster, and M. E. Rothenberg, "Chemokines in asthma: cooperative interaction between chemokines and IL-13," Journal of Allergy and Clinical Immunology, vol. 111, no. 2, pp. 227-243, 2003.

[26] O. Kaminuma, A. Mori, N. Kitamura et al., "Role of GATA-3 in IL-5 gene transcription by CD $4{ }^{4} \mathrm{~T}$ cells of asthmatic patients," 
International Archives of Allergy and Immunology, vol. 137, pp. 55-59, 2005.

[27] R. E. Mullings, S. J. Wilson, S. M. Puddicombe et al., "Signal transducer and activator of transcription 6 (STAT-6) expression and function in asthmatic bronchial epithelium," Journal of Allergy and Clinical Immunology, vol. 108, no. 5, pp. 832-838, 2001.

[28] V. J. Erpenbeck, J. M. Hohlfeld, M. Discher et al., "Increased expression of interleukin-9 messenger RNA after segmental allergen challenge in allergic asthmatics," Chest, vol. 123, no. 3 , p. 370S, 2003.

[29] J. C. Kips, "Cytokines in asthma," The European Respiratory Journal. Supplement, vol. 34, pp. 24s-33s, 2001.

[30] A. C. D. Silva, R. P. Vieira, M. Nisiyama et al., "Exercise inhibits allergic lung inflammation," International Journal of Sports Medicine, vol. 33, no. 5, pp. 402-409, 2012.

[31] C. R. Olivo, R. P. Vieira, F. M. Arantes-Costa, A. Perini, M. A. Martins, and C. R. F. Carvalho, "Effects of aerobic exercise on chronic allergic airway inflammation and remodeling in guinea pigs," Respiratory Physiology and Neurobiology, vol. 182, no. 2-3, pp. 81-87, 2012.

[32] A. Pastva, K. Estell, T. R. Schoeb, T. P. Atkinson, and L. M. Schwiebert, "Aerobic exercise attenuates airway inflammatory responses in a mouse model of atopic asthma," Journal of Immunology, vol. 172, no. 7, pp. 4520-4526, 2004.

[33] R. P. Vieira, A. C. Toledo, L. B. Silva et al., "Anti-inflammatory effects of aerobic exercise in mice exposed to air pollution," Medicine and Science in Sports and Exercise, vol. 44, no. 7, pp. 1227-1234, 2012.

[34] R. Michishita, N. Shono, T. Inoue, T. Tsuruta, and K. Node, "Effect of exercise therapy on monocyte and neutrophil counts in overweight women," American Journal of the Medical Sciences, vol. 339, no. 2, pp. 152-156, 2010.

[35] V. Luks, A. Burkett, L. Turner, and S. Pakhale, "Effect of physical training on airway inflammation in animal models of asthma: a systematic review," BMC Pulmonary Medicine, vol. 13, no. 1, article 24, 2013.

[36] A. Moreira, L. Delgado, T. Haahtela et al., "Physical training does not increase allergic inflammation in asthmatic children," European Respiratory Journal, vol. 32, no. 6, pp. 1570-1575, 2008.

[37] K. Backteman and J. Ernerudh, "Biological and methodological variation of lymphocyte subsets in blood of human adults," Journal of Immunological Methods, vol. 322, no. 1-2, pp. 20-27, 2007.

[38] P. Duramad, C. W. McMahon, A. Hubbard, B. Eskenazi, and N. T. Holland, "Flow cytometric detection of intracellular Th1/Th2 cytokines using whole blood: validation of immunologic biomarker for use in epidemiologic studies," Cancer Epidemiology Biomarkers and Prevention, vol. 13, no. 9, pp. 14521458, 2004.

[39] V. Orrù, M. Steri, G. Sole et al., "Genetic variants regulating immune cell levels in health and disease," Cell, vol. 155, no. 1, pp. 242-256, 2013.

[40] S. A. M. Heikkinen, R. Quansah, J. J. K. Jaakkola, and M. S. Jaakkola, "Effects of regular exercise on adult asthma," European Journal of Epidemiology, vol. 27, no. 6, pp. 397-407, 2012. 


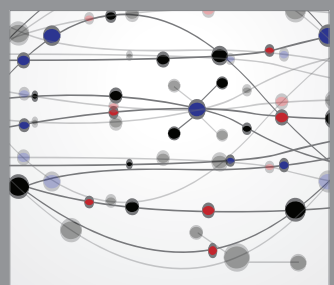

The Scientific World Journal
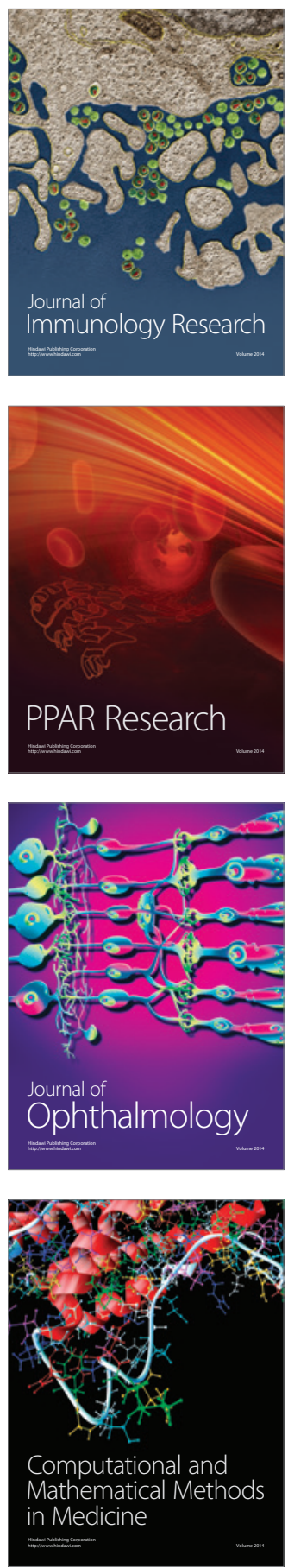

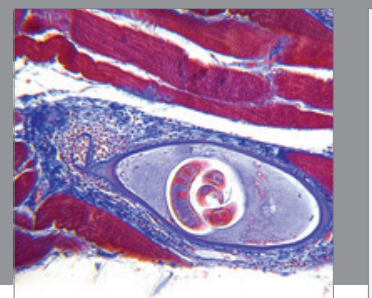

Gastroenterology

Research and Practice
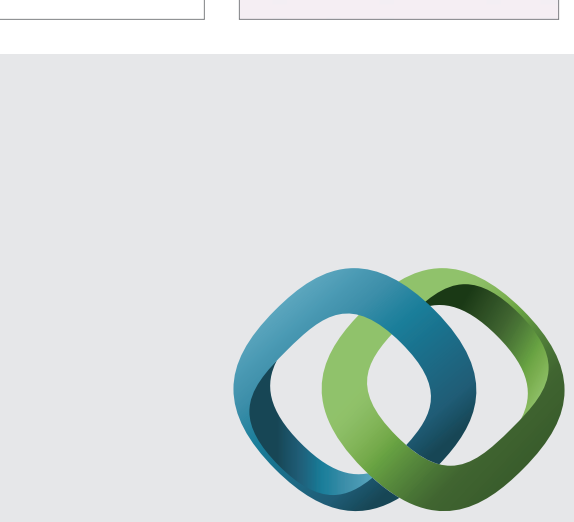

\section{Hindawi}

Submit your manuscripts at

http://www.hindawi.com
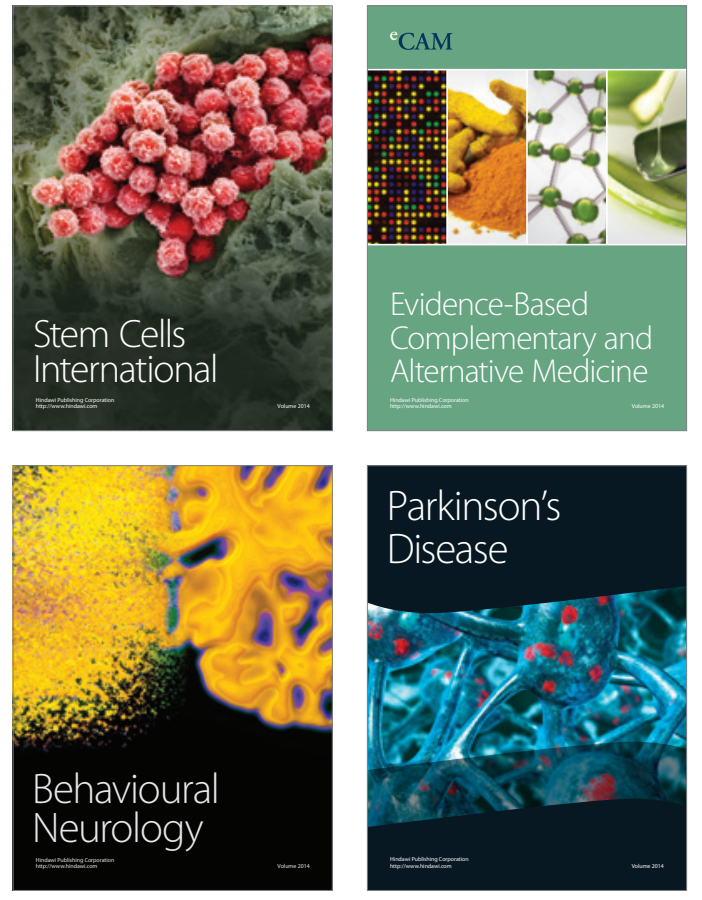
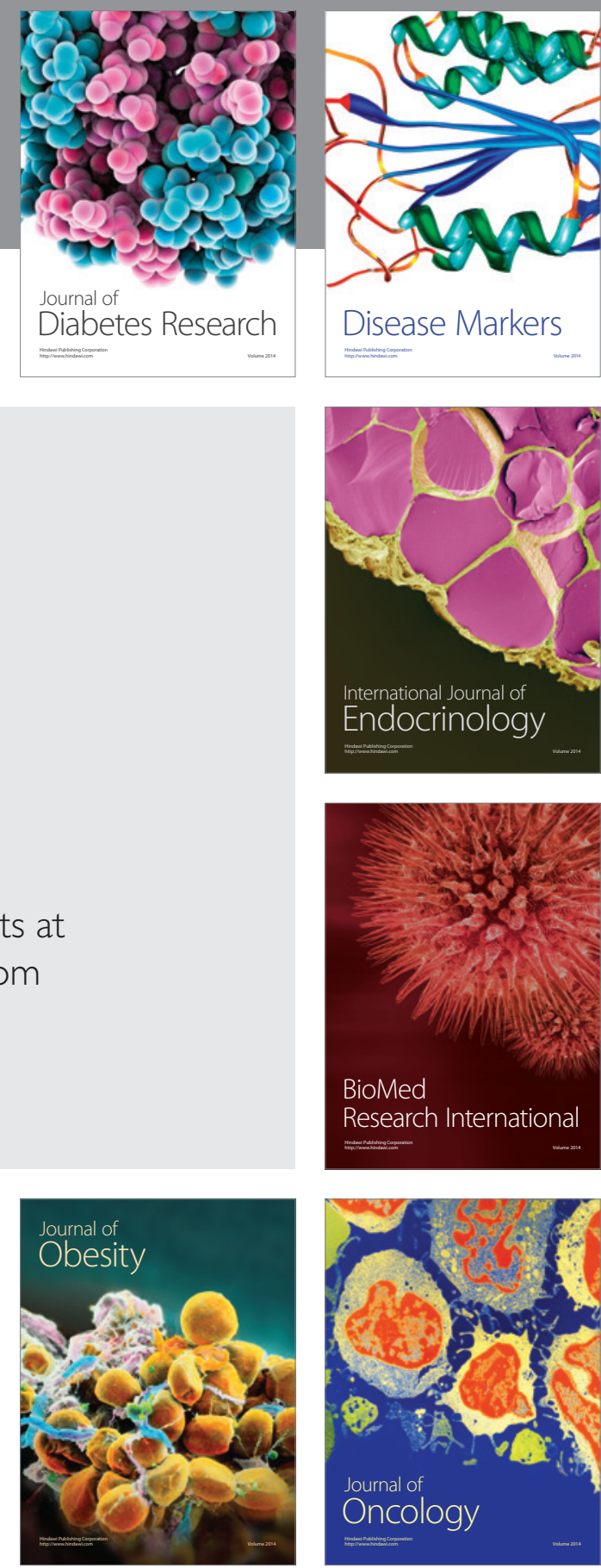

Disease Markers
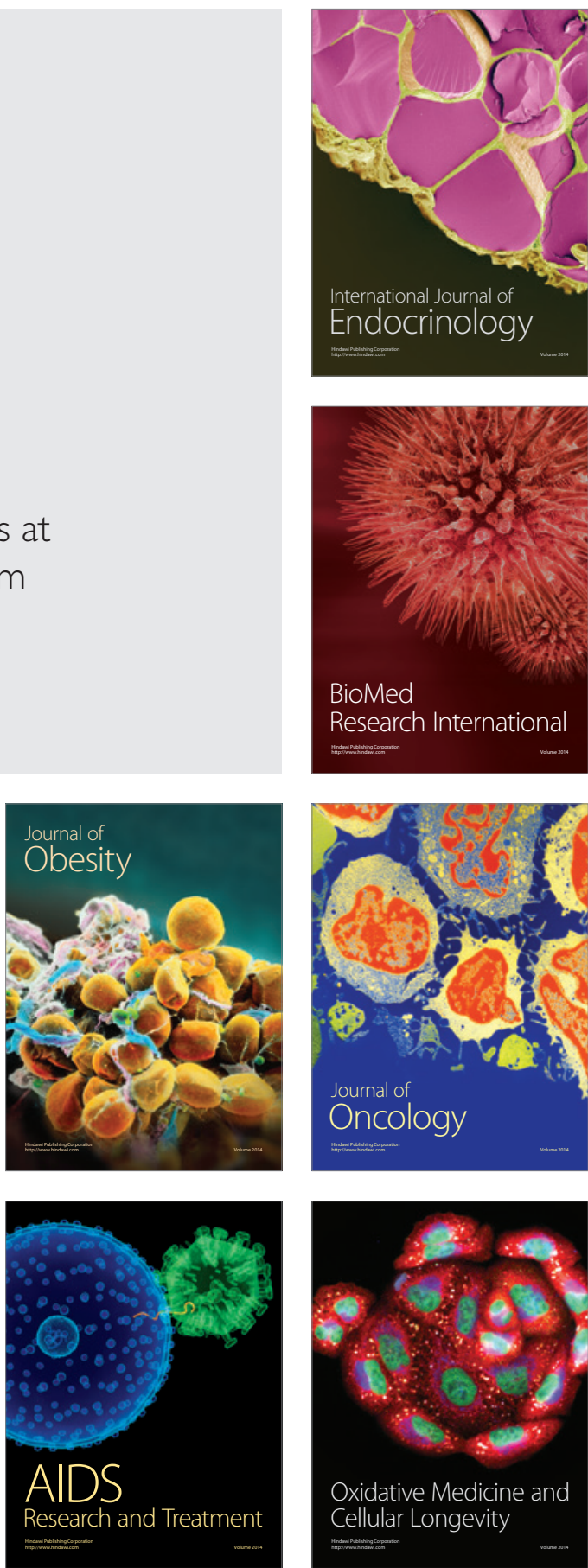